\title{
Du territoire au terrain : Pour une histoire des deux ethnologies allemandes
}

Jean-Louis Georget

\section{(2) OpenEdition}

\section{Journals}

Édition électronique

URL : http://journals.openedition.org/ifha/8077

DOI : $10.4000 /$ ifha. 8077

ISSN : 2198-8943

\section{Éditeur}

IFRA - Institut franco-allemand (sciences historiques et sociales)

\section{Édition imprimée}

Date de publication : 31 décembre 2014

ISSN : 2190-0078

\section{Référence électronique}

Jean-Louis Georget, "Du territoire au terrain : Pour une histoire des deux ethnologies allemandes », Revue de l'IFHA [En ligne], 6 | 2014, mis en ligne le 31 décembre 2014, consulté le 21 avril 2019. URL : http://journals.openedition.org/ifha/8077 ; DOI : 10.4000/ifha.8077

Ce document a été généré automatiquement le 21 avril 2019

(CIFHA 


\title{
Du territoire au terrain: Pour une histoire des deux ethnologies allemandes
}

\author{
Jean-Louis Georget
}

1 L'ouvrage original du travail d'habilitation de Monsieur Georget, intitulé « Pour une autre histoire de la Volkskunde", est consacré à l'histoire de l'ethnologie allemande. La question est abordée de manière chronologique et le propos organisé en cinq parties courant du XVIIIe siècle au milieu du XXe siècle. Partant du constat d'une lacune, la recherche s'intéresse à la généalogie de la discipline en Allemagne, une discipline présentant la particularité, en comparaison avec ses voisines française et britannique, de se séparer en deux branches, la première, Völkerkunde, se consacrant aux groupes ethniques étrangers, tandis que la Volkskunde s'est concentrée sur la germanité et le territoire germanique. L'auteur de l'ouvrage interroge les circonstances et formes de l'apparition de la discipline, son devenir et sa transformation au fil des décennies, mais aussi son périmètre incertain, ses contours souvent aussi fluctuants que son objet, ainsi que les théories et outils conceptuels qui l'ont traversée et en partie structurée en réaction aux bouleversements territoriaux et de pouvoir dans l'espace langue allemande. Cette construction particulière de la discipline est identifiée comme spécificité allemande, rattachant à un "peuple» - d'autant plus aisément essentialiste et manipulé qu'il a été qualifié par le très polysémique Volk - des réalités qui ont été appréhendées dans les pays voisins par l'histoire ou la sociologie. La période se discipline prend forme et force en Allemagne se situe à la fin du XIXe siècle, mais l'auteur remonte plus avant dans le temps pour tenter d'en retrouver les origines qu'il place au XVIIIe siècle. Cet effort de vouloir retracer la généalogie d'une discipline universitaire qui produisit au fil des décennies un discours sur soi plus marqué par l'élaboration d'un mythe, donc anhistorique, que par la clarté est louable et nécessaire. Ce travail de recherche livre une indispensable histoire à la fois intellectuelle et institutionnelle de l'ethnologie allemande et dresse un tableau très précis des universitaires présents dans les différentes universités de l'espace germanophone et circulant entre l'entre la fin du XIXe siècle 1945. 
L'auteur défend la thèse que c'est à la suite de la victoire de la Prusse en Autriche à Sadowa en 1866 qu'a pu naître et s'épanouir l'ethnologie allemande appliquée aux Allemands dans un contexte de recompositions territoriale et à partir d'une incertitude identitaire qui fut exacerbée par le rejet de l'Autriche à la périphérie de la nation. Il retrace les heurs de la discipline universitaire entre l'Autriche et la Prusse/Empire et le développement des musées ethnographiques, après avoir trouvé les facteurs de son émergence comme science rattachée au caméralisme pour répondre aux conséquences démographiques de conflits dans l'Empire ainsi qu'à la montée en puissance de l'État monarchique prussien dans un ensemble d'Etats territoriaux hétérogènes dans l'espace allemand. Il montre le rôle qui a été attribué à l'ethnologie dans la valorisation de la langue allemande comme ciment de l'État bismarckien et dans la construction du mythe du peuple permettant de subsumer toutes les différences territoriales. Enfin il démontre comment la focalisation sur la culture populaire centrée sur le paysan a fixé les conditions favorables au dévoiement des notions dans la révolution conservatrice et la mise au pas de la discipline à partir de 1933. Les développements sur le troisième Reich constituent une contribution originale à l'histoire des institutions de savoir et à l'histoire des intellectuels sous le nazisme.

2 La première grande idée de ce travail est donc que la Volkskunde naît véritablement sur les marges de la germanité et chez les vaincus de la guerre austro-allemande ou encore, formulée différemment, est à la fois l'histoire de ces marges germanophones restées à l'écart de l'Allemagne politique et la retenue des possibles évanouis. La seconde est que la Volkskunde est une science de la continuité d'une germanité idéelle, qui répondait aux fractures du territoire germanophone malmené par l'histoire. Cette question pose également celle de l'historicité du concept de Volk en général et de celui que met en œuvre plus particulièrement la Volkskunde. La troisième idée importante est que dans l'ethnologie allemande, la philologie est venue se greffer sur un savoir administratif et juridique et que l'on a donc une double appartenance épistémologique aux domaines juridique et philologique.

\section{AUTEUR}

JEAN-LOUIS GEORGET

(IFHA) 